\title{
Effect of the intake of high or low glycemic index high carbohydrate- meals on athletes' sleep quality in pre-game nights
}

\author{
NATÁLIA V.S. DANIEL ${ }^{1}$, IONÁ Z. ZIMBERG ${ }^{2}$, DEBORA ESTADELLA ${ }^{3}$, MÁRCIA \\ C. GARCIA ${ }^{3}$, RICARDO C. PADOVANI ${ }^{4}$ and CLAUDIA R. JUZWIAK ${ }^{5}$ \\ ${ }^{1}$ Pós-Graduação Interdisciplinar em Ciências da Saúde, Universidade Federal de São Paulo/ \\ UNIFESP, Av. Ana Costa, 95, Vila Mathias, 11060-001 Santos, SP, Brazil \\ ${ }^{2}$ School of Public Health and Preventive Medicine, Monash University, Wellington \\ Road, Clayton, Victoria 3800, Melbourne, Australia \\ ${ }^{3}$ Departamento de Biociências, Universidade Federal de São Paulo/UNIFESP, \\ Rua Silva Jardim, 136, 11015-020 Santos, SP, Brazil \\ ${ }^{4}$ Departamento de Saúde, Educação e Sociedade, Universidade Federal de São Paulo/ \\ UNIFESP, Rua Silva Jardim, 136, 11015-020 Santos, SP, Brazil \\ ${ }^{5}$ Departamento de Ciências do Movimento Humano, Universidade Federal de São Paulo/ \\ UNIFESP, Rua Silva Jardim, 136, 11015-020 Santos, SP, Brazil \\ Manuscript received on January 31, 2018; accepted for publication on May 4, 2018
}

\begin{abstract}
How to cite: DANIEL NVS, ZIMBERG IZ, ESTADELLA D, GARCIA MC, PADOVANI RC AND JUZWIAK CR. 2019. Effect of the intake of high or low glycemic index high carbohydrate-meals on athletes' sleep quality in pre-game nights.. An Acad Bras Cienc 91: e20180107. 10.1590/0001-3765201920180107.
\end{abstract}

\begin{abstract}
This study investigated the effect of the intake of high (HGI) or low glycemic index (LGI) high-carbohydrate meals on athletes' sleep. Nine basketball adult male athletes were assessed during a championship and received high-carbohydrate meals (dinner and evening snack) with HGI or LGI. Quantitative and qualitative sleep variables were assessed: sleep latency (LAT), sleep efficiency (EFIC), Wake After Sleep Onset (WASO), sleep time through actigraphy and sleep diary. Dietary intake, satiety, sleepiness, glycemic response, salivary cortisol and melatonin were also assessed. On both days most athletes had LAT and WASO higher than recommendation, and nocturnal sleep time below the recommendations. There was no difference between sleep and hormonal parameters according to GI dietary manipulations; however, correlations were observed between sleep and diet. Daily energy intake had negative correlation with efficiency and nocturnal total sleep time, and a positive correlation with WASO, regardless of the GI nocturnal meals. No differences were observed in salivary cortisol and melatonin according to GI. The results suggest that food intake throughout the day seems to exert more influence on sleep parameters of basketball players than GI manipulation of evening meals on the pre-night game, but further studies are necessary to better understand this complex relationship.
\end{abstract}

Key words: sleep, glycemic index, athletes, dietetics.

Correspondence to: Natália Vilela Silva Daniel

E-mail: natalia.vilelasd@gmail.com

ORCid: https://orcid.org/0000-0002-8959-943X 


\section{INTRODUCTION}

Diet plays an important role in athletes' performance (ACSM 2016). Among several dietary strategies used to optimize athletic performance, there is a consensus about the importance of carbohydrate intake before competitions (Burke et al. 2011, ACSM 2016). Studies show that diet can affect sleep (Afaghi et al. 2007, Lindseth et al. 2013, Nehme et al. 2014, Peuhkuri et al. 2012), and sleep can impact on athletic performance (Jullif et al. 2015). Athletes with sleep deprivation present impaired aerobic performance (Oliver et al. 2009) and reaction time (Taheri and Arabameri 2012), negative changes in mood (Scott et al. 2006), increased perceived exertion, and reduced time to exhaustion (Antunes et al. 2008).

Diet has been pointed out as a non-medical alternative to improve sleep. Studies conducted with non-athletes suggest that glycemic index (GI) manipulation can affect sleep, since high GI food intake reduced sleep onset latency (Afaghi et al. 2007). Besides latency, high GI was further associated with longer sleep duration (Diethelm et al. 2011) and with a better usual sleep quality (Yoneyama et al. 2014). However, the effect of manipulating athletes' diet on sleep has only been evaluated in one study (Killer et al. 2015). The ingestion of carbohydrate-rich drinks before, during and after a cycling training [totalizing 9.9(1.5) g/ $\mathrm{kg} /$ day] was associated with lower sleep time than in control group (without carbohydrate increase) [7.4(1.6) $\mathrm{g} / \mathrm{kg} / \mathrm{day}]$, and the authors suggested that control group would need more sleep time to exercise recover (Killer et al. 2015).

Considering the lack of studies which investigate the variables related to sleep quality in athletes, we aimed to examine the effect of high (HGI) or low (LGI) glycemic index (GI) carbohydrate-rich meals on sleep parameters during a competition. The hypothesis was that HIG carbohydrate-rich meals would reduce sleep latency, resulting in better sleep quality on a precompetitive night.

\section{MATERIALS AND METHODS}

\section{PARTICIPANTS}

Nine high-performance male, adult, basketball players, from a city in São Paulo state, Brazil, who participated in a state championship volunteered to participate in this study. Participants were included only if they agreed to follow the proposed diet, did not take medications related to sleep and did not have diseases directly related to carbohydrate metabolism. Before participation, athletes received verbal and written information about the study, and provided written informed consent. The study was approved by the Research Ethics Committee of the Universidade Federal de São Paulo, under appraisal \#921.341/14.

\section{STUDY DESIGN AND PROCEDURES}

This is a cross-sectional study with a crossover design. Data was collected during three days (Figure 1) of a state championship.

One week before competition, participants answered a questionnaire about training characteristics and food history. Athletes went through anthropometric (body mass, height) and skinfold assessment, according to the recommendations of the International Standards for Anthropometric Assessment (ISAK 2001). Body mass index was estimated as well as body density (Jackson and Pollock 1978), which was converted to body fat percentage using Siri equation (1961).

Blood samples were collected in the morning (after 8 hours fasting) and glycaemia and lipid profile (cholesterol and triacylglycerol) were analyzed using Accu-chek ${ }^{\circledR}$ glycosimeter (Roche Ltd, Mannheim, Germany) and Accutrend ${ }^{\circledR}$ Plus glycosimeter (Roche Ltd, Mannheim, Germany), respectively. 


\begin{tabular}{|l|l|l|}
\hline DAY1 & DAY2 & DAY3 \\
\hline
\end{tabular}

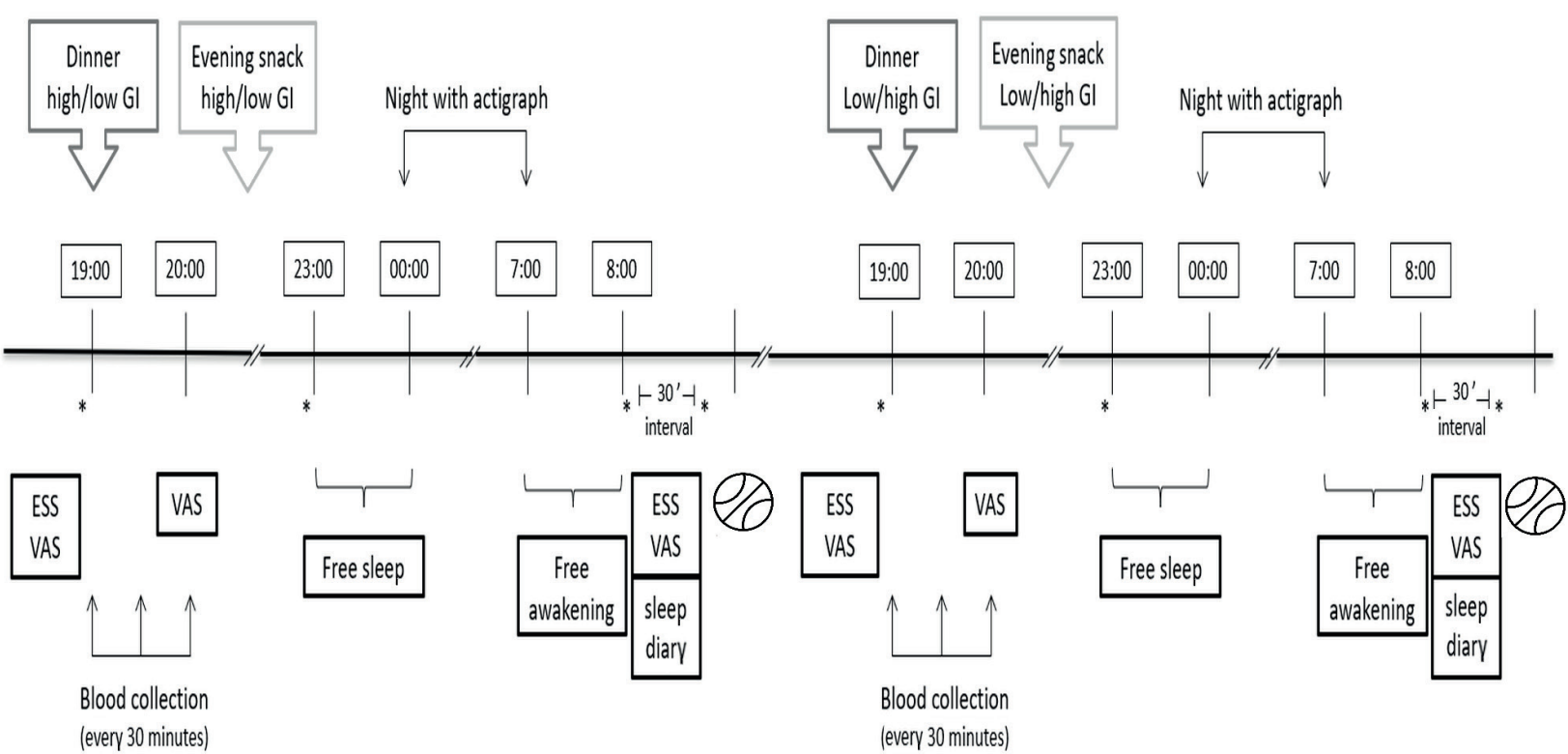

Figure 1 - Experimental study protocol.

*Saliva collection; basketball ball=basketball game. ESS=Epworth Sleepiness Scale; VAS=Visual Analogous Scale (for satiety and sleepiness). Blood collection was performed every 30 minutes after starting dinner intake.

To identify usual sleep quality, athletes answered the Pittsburgh Sleep Quality Index (PSQI) questionnaire (Bertolazi 2008), which classifies individuals with good $(<5)$ or poor sleep quality ( $\geq 5$ ) (Buysse et al. 1989). Aiming to evaluate chronotype, the Brazilian version of the Morningness-eveningness questionnaire (MEQ) was applied (Benedito-Silva et al. 1990). MEQ classification is: definite evening (16-30 points), moderate evening (31-41), intermediate (42-58), moderate morning (59-69) or definite morning (7086) (Horne and Ostberg 1976).

All games were held in the morning (9h-12h), in two consecutive days. During the competition, athletes slept in a school, with mattresses disposed on classroom floor. The classroom had curtains on the windows, and athletes reported that the ambient light in the morning did not cause discomfort.

\section{DIETARY INTERVENTION}

The manipulated meals provided were defined based on athletes' habits and approved by participants. Except for the intervention meals (dinner and evening snack - ES), athletes' intake throughout the day was ad libitum. All food and drink consumed during the study were registered for dietary calculation (Nutrition Data System for Research $^{\circledR}$ software). Participants were instructed not to consume coffee during data collection.

Athletes were randomly distributed in two groups, following the crossover design. Individuals consumed dinner and ES (Table I) on the nights of the first and second competition days. 
TABLE I

Meals food composition (dinner and evening snack) with high and low GI.

\begin{tabular}{|c|c|c|c|c|}
\hline GI & Dinner & *GI & Evening snack & *GI \\
\hline High & $\begin{array}{l}\text { White rice, cow meat (grilled), potato (without } \\
\text { skin, baked), Gatorade }{ }^{\mathbb{B}} \text { (tangerine flavor), jelly } \\
\text { beans }\end{array}$ & 74.9 & $\begin{array}{l}\text { Orange juice (unsweetened, reconstituted } \\
\text { concentrate), cornflakes, cookie (honey and } \\
\text { cocoa flavor), sandwich (white bread with } \\
\text { butter and skim milk cheese) }\end{array}$ & 71.8 \\
\hline Low & $\begin{array}{l}\text { White rice, carioca beans, cow meat (grilled), } \\
\text { apple juice (whole, unsweetened), cereal (rich in } \\
\text { fiber), yogurt (whole milk, artificial strawberry } \\
\text { flavored) }\end{array}$ & 49.5 & $\begin{array}{l}\text { Chocolate milk, apple, cereal bar (hazelnut } \\
\text { flavor), sandwich (white bread with butter } \\
\text { and skim milk cheese) }\end{array}$ & 47.9 \\
\hline
\end{tabular}

*GI calculated using Wolever and Jenkins (1986) protocol.

GI meal values were estimated using Wolever and Jenkins (1986) method, and GI was classified as: low $(\leq 55)$, medium $(56-69)$ or high $(\geq 70)$ GI (Atkinson et al. 2008). High and low-GI dinners and ES were isocaloric ( $\mathrm{p}=0.22)$, and the dietary composition of meals are described in Table II.

On evaluation days, athletes were fasted for 3 hours. Blood collection for glycemic response analysis was conducted before dinner, 30 minutes and 60 minutes after the start of dinner. Participants agreed to eat dinner in a maximum 15 minutes interval (Afaghi et al. 2007). After dinner, athletes received a kit containing the $\mathrm{ES}$, which also met the GI (high/low) consumed at dinner of the same day.

Before and immediately after dinner, participants answered to a visual analogous scale (VAS) (10cm) (Hindmarch 1980) to evaluate satiety, which contained the words "hungry" and "extremely satisfied" at the extremities (Afaghi et al. 2007).

\section{SLEEP EVALUATION}

Athletes were free to sleep and wake up whenever they wanted. The sleep pattern was assessed using an Ambulatory Monitorning Inc ${ }^{\circledR}$ actigraph (New York, USA), and data was read by Action- $\mathrm{W}^{\circledR}$ software (2.6 version, Ambulatory Monitorning, USA). The actigraph was used on non-dominant arm, and the parameters considered were: nocturnal total sleep time (NTST), daytime total sleep time (DTST), sleep efficiency (EFIC) (time of sleep divided by total time in bed), sleep latency (LAT) (time after lying down until sleep) and Wake After Sleep Onset (WASO).

Participants informed their bedtime and awakening time, if they woke up at night and how many times, and their subjective sleep quality (SSQ) (10cm scale) in a sleep diary. A VAS was used to assess sleepiness, which was indicated on a $10 \mathrm{~cm}$ line with the words "not sleepy" or "sleepy" at the extremities (Afaghi et al. 2007). The Epworth Sleepiness Scale (ESS) (Bertolazi et al. 2009) was used to assess the daytime sleepiness. Results above 9 were considered as excessive daytime sleepiness. Individuals answered to VAS and ESS before dinner and in morning after meals manipulations.

\section{HORMONAL ANALYSIS}

Melatonin secretion was analyzed by salivary dosage (ELISA kit-IBL ${ }^{\circledR}$ International GMBH, Germany). Saliva collection was performed before dinner, before bedtime ( $\geq 60$ minutes after ES) and right after awakening (still in bed), in the subsequent morning. Athletes received plastic tubes (salivettes ${ }^{\circledR}$, Sarstedt, Numbrecht, Germany) with specific cotton for saliva collection and were instructed according to kit recommendations. Saliva samples were stored in a freezer at $-5^{\circ} \mathrm{C}$ for three days, transported under refrigeration, and afterwards stored in a freezer at $-20^{\circ} \mathrm{C}$.

Cortisol levels were also evaluated through salivary cortisol dosage. The collection followed the same procedures described above, but with an additional collection point, 30 minutes after the 
TABLE II

Meals food composition (dinner and evening snack) with high and low GI.

\begin{tabular}{|c|c|c|c|c|c|c|c|c|}
\hline & & $\begin{array}{l}\text { Energy } \\
\text { (kcal) }\end{array}$ & $\begin{array}{c}\text { Carbohydrate } \\
\text { (g) }\end{array}$ & $\begin{array}{c}\text { Carbohydrate } \\
\text { (\%meal) }\end{array}$ & $\begin{array}{l}\text { Protein } \\
\text { (g) }\end{array}$ & $\begin{array}{l}\text { Protein } \\
\text { (\%meal) }\end{array}$ & $\begin{array}{l}\text { Fat } \\
\text { (g) }\end{array}$ & $\begin{array}{c}\text { Fat } \\
\text { (\%meal) }\end{array}$ \\
\hline \multirow{2}{*}{ HGI } & Dinner & 833 & 130.8 & 62.8 & 36.2 & 17.4 & 18.4 & 19.9 \\
\hline & ES & 1058 & 169.5 & 64.1 & 27.9 & 10.5 & 29.9 & 25.4 \\
\hline \multirow{2}{*}{ LGI } & Dinner & 924 & 129.9 & 56.2 & 47.5 & 20.6 & 23.8 & 23.2 \\
\hline & ES & 1083 & 160.3 & 59.2 & 33.1 & 12.2 & 34.4 & 28.6 \\
\hline
\end{tabular}

$\mathrm{ES}=$ evening snack; \%meal=percentage of the meal (dinner or evening snack).

first collection in the morning, at fast. Analysis was performed using a commercial Cortisol kit (Salimetrics $^{\circledR}$, LLC, State College, PA, USA).

Information of temperature and air relative humidity was collected online (www.climatempo. com.br). Athletes' perceived exertion was evaluated through the Borg (1982) scale (0-10 scale).

\section{STATISTICAL ANALYSIS}

Data were analyzed by Graph Pad Prism software (5.01 version) and presented as median, minimum and maximum values and standard deviation. D'Agostino and Pearson test was applied to evaluate the normality of data distribution, while Levene's was used to homogeneity test. Considering the results and the small sample size, non-parametric statistical tests were adopted. The results of sleepiness, satiety, cortisol and melatonin were compared according to GI by Friedman test, followed by Dunn's Posthoc for multiple comparisons. To investigate the difference between sleep parameters, daytime sleepiness and food consumption according to the GI, Wilcoxon's test was applied. The glycemic response after dinner GI manipulation was evaluated using the area under the curve (AUC) of the two situations (HGI/ LGI), which were compared using Wilcoxon's test. To evaluate the association between sleep parameters and the other factors and between food consumption and other parameters, Spearman's correlation coefficient was calculated. Statistical significance was set at $\mathrm{p}<0.05$.

\section{RESULTS}

Participants were $18.0 \pm 0.7$ years old, and presented mean values of $90.0 \pm 10.9 \mathrm{~kg}$ of body mass, $1.95 \pm 0.1 \mathrm{~m}$ of height, $23.9 \pm 1.5 \mathrm{~kg} / \mathrm{m}^{2}$ of Body Mass Index, and $10.6 \pm 3.2 \%$ of body fat percentage. Athletes had $7.0 \pm 4.5$ years of basketball practice and trained $17.5 \pm 5.0$ hours per week. The general daily exercise activities and duration reported by the athletes were two hours of general basketball training, half an hour of shooting baskets training and one hour of resistance (weight) training.

Fasted glycaemia, cholesterol and triacylglycerol were $96.0 \pm 6.3 \mathrm{mg} / \mathrm{dL}, 151.0 \pm 6.6$ $\mathrm{mg} / \mathrm{dL}$ and $80.0 \pm 11.8 \mathrm{mg} / \mathrm{dL}$, respectively. Mean PSQI score was of 5.5 (3.2). Five (56\%) had a PSQI score $>5$, indicating poor sleep quality. Six $(67 \%)$ athletes were classified as chronotype "intermediate", two (22\%) as "moderate morning" and one (11\%) as "definite evening".

Perceived exertion (Borg 1982) was 4.5 (1.5) (3-7) before HGI and 5.0 (1.8) (3-8) before LGI, with no significant difference. Ambient temperature $\left(25^{\circ} \mathrm{C}\right.$ and $\left.24^{\circ} \mathrm{C}\right)$, relative air humidity $(100 \%$ and $97 \%$ ) were similar on both days.

\section{RESPONSE TO DIETARY INTERVENTION}

Table III shows energy and macronutrients intakes on intervention days. Only carbohydrate intake (g/ $\mathrm{kg} / \mathrm{d}$ ) was significantly different according to GI $(\mathrm{p}=0.04)$. After an individual analysis, it was noted that six athletes consumed more rice at lunch in 
HGI day, resulting in higher daily carbohydrate intake.

There was a significant difference between the AUCs after HGI [237.0 (18.4)] and LGI [217.8 (19.8)] $(\mathrm{p}=0.006)$, indicating that the HGI glycemic response was higher than LGI, as expected (not shown). Glycemic response were 98.00 (9.3) and $99.0(5.6) \mathrm{md} / \mathrm{dL}$ before dinner, 132.0 (15.9) and $120.0(18.6) \mathrm{md} / \mathrm{dL} 30$ minutes after the start of dinner, and 110.0 (18.7) and 100.0 (9.5) $\mathrm{md} / \mathrm{dL} 60$ minutes after the start of dinner, in HGI and LGI, respectively.

There was no difference in satiety according to GI [HGI: before dinner (BD) 2.4 (2.4); after dinner (AD) 5.8 (1.7); before breakfast (BB) 5.2 (2.1); LGI: BD 1.1 (2.0); AD 6.1 (1.9); BB 4.2 (2.2)] (no shown).

No significant differences were observed in sleepiness (VAS) in relation to GI. On HGI night, athletes' sleepiness scores were of 4.7 (2.9) BD; 4.9 (2.6) AD; and 4.5 (2.4) BB, whereas in LGI the sleepiness results were 4.0 (1.8) BD; 4.0 (1.4) $\mathrm{AD}$; and 5.4 (2.4) BB (no shown). There was a negative correlation between LGI carbohydrate intake and sleepiness $\mathrm{AD}(\mathrm{r}=0.70 ; \mathrm{p}=0.04)$. A positive correlation was also observed after LGI, between $\mathrm{AD}$ sleepiness and subjective sleep quality (SSQ) $(\mathrm{r}=0.75, \mathrm{p}=0.02)$, and a negative correlation between SSQ and sleepiness BD $(r=-0.73, p=0.02)$. Concerning daytime sleepiness (ESS), it was observed that, regardless of the moment and GI, athletes presented excessive daytime sleepiness $(>9)$ (Figure 2), with no statistical difference according to GI.

HGI daytime sleepiness had a positive correlation with the daily percentage of carbohydrate intake in relation to total energy value (CHO \%EI) (r=0.77, p=0.02; r=0.90, p=0.001), and negative with daily protein intake $(\mathrm{g} / \mathrm{kg})(\mathrm{r}=-0.77$, $\mathrm{p}=0.02 ; \mathrm{r}=-0.85, \mathrm{p}=0.004)$, both at night and in the subsequent morning, respectively.

Table IV presents the results of sleep parameters evaluated by actigraphy. There was no statistical difference in sleep parameters according to GI. In HGI, 38\% of the athletes had lower latency than recommended (30 minutes), whereas in LGI only $25 \%$ of them were below the recommendation. Regarding efficiency, in both nights $75 \%$ of the subjects were above the recommendation (85\%), indicating satisfactory sleep efficiency. As for WASO, after HGI only one athlete was below the recommended limit ( $<30$ minutes), while after LGI four athletes presented WASO values for adequate sleep.

Most athletes napped (daytime sleep) during both days. In the afternoon following HGI, seven athletes slept after lunch, and after LGI, eight athletes napped in the afternoon. No significant differences were found in daytime sleep according to GI.

No significant difference in subjective sleep quality was found between HGI [5.2 (1.4)] and LGI [4.0 (2.1)] nights. Figure 3 shows the nocturnal sleep parameters, compared to literature recommendations.

There were significant correlations between energy intake and sleep efficiency (HGI: $r=-0.77$; $\mathrm{p}=0.01$; LGI: $\mathrm{r}=-0.84 ; \mathrm{p}=0.03$ ) and WASO (HGI: $\mathrm{r}=0.77 ; \mathrm{p}=0.03$; LGI: $\mathrm{r}=0.74 ; \mathrm{p}=0.03$ ).

Most athletes woke up at least one time in both nights ( $89 \%$ after HGI and $67 \%$ after LGI), but there was no significant difference in number of awakenings. Athletes indicated the bad quality of the mattresses and external noises at night (other teams) as the main reasons for awakenings.

In relation to salivary cortisol, no significant differences were observed according to GI, only between moments (Table V). The results showed an expected circadian rhythm, with lower levels at night and peak of greater levels at awakening. BD cortisol level on HGI was negatively correlated with sleep efficiency $(\mathrm{r}=-0.85, \mathrm{p}=0.01)$ and positively with WASO $(\mathrm{r}=0.85, \mathrm{p}=0.01)$. Correlations between these variables were also observed after awakening (AA) (sleep efficiency: $r=-0.71, p=0.05$; 
TABLE III

Daily dietary information according to the GI consumed at evening meals $(n=9)$.

\begin{tabular}{lcccc}
\hline & HGI & Min-max & LGI & Min-max \\
\hline Energy $(\mathrm{kcal} / \mathrm{kg})$ & $42(5)$ & $34-48$ & $41(4)$ & $35-47$ \\
Fat $(\mathrm{g} / \mathrm{kg})$ & $1.2(0.2)$ & $0.8-1.4$ & $1.2(0.2)$ & $1.0-1.5$ \\
Protein $(\mathrm{g} / \mathrm{kg})$ & $1.8(0.49)$ & $1.4-2.8$ & $2.1(0.4)$ & $1.4-2.9$ \\
Carbohydrate $(\mathrm{g} / \mathrm{kg})$ & $* 5.8(0.7)$ & $4.9-6.8$ & $5.4(0.7)$ & $4.7-6.8$ \\
Carbohydrate $(\% \mathrm{VET})$ & $57.0(3.5)$ & $52.1-62.8$ & $55.0(3.7)$ & $47.0-58.0$ \\
\hline
\end{tabular}

Values expressed as median (standard deviation). *Carbohydrate intake significantly higher on the day of HGI in relation to LGI $(\mathrm{p}=0.04)$.

TABLE IV

Sleep parameters according to dietary GI $(n=8)$.

\begin{tabular}{|c|c|c|c|c|}
\hline & HGI & Min-max & LGI & Min-max \\
\hline Nocturnal total sleep time (minutes) & $386.0(74.9)$ & $207-436$ & $359.5(56.7)$ & $276-438$ \\
\hline Daytime total sleep time (minutes) & $98.0(45.9)$ & $37-176$ & $101.0(29.4)$ & $94-166$ \\
\hline Total sleep time (nocturnal + daytime) (minutes) & $504.5(86.3)$ & $299-538$ & $433.5(86.9)$ & $338-604$ \\
\hline Nocturnal sleep latency (minutes) & $33.5(22.0)$ & 4-71 & $46.0(46.8)$ & $3-150$ \\
\hline Daytime sleep latency (minutes) & $10.0(14.7)$ & $1-38$ & $13.0(12.9)$ & $3-34$ \\
\hline Nocturnal sleep efficiency (\%) & $89.9(9.9)$ & $66-98$ & $91.1(6.1)$ & $79-96$ \\
\hline Daytime sleep efficiency (\%) & $90.2(9.8)$ & $73.2-100$ & $94.9(8.1)$ & $78.9-99.0$ \\
\hline WASO of nocturnal sleep (minutes) & $43.0(31.5)$ & $10-108$ & $34.0(27.3)$ & $17-94$ \\
\hline WASO of daytime sleep (minutes) & $10.0(20.4)$ & $0-56$ & $9.0(10.4)$ & $1-27$ \\
\hline
\end{tabular}

Values expressed in median (standard deviation), minimum-maximum. WASO=Wake After Sleep Onset. At the moment of reading the data, the record of one of the nine evaluated athletes was not stored in the actigraph, therefore it could not be analyzed ( $\mathrm{n}=8$ ).

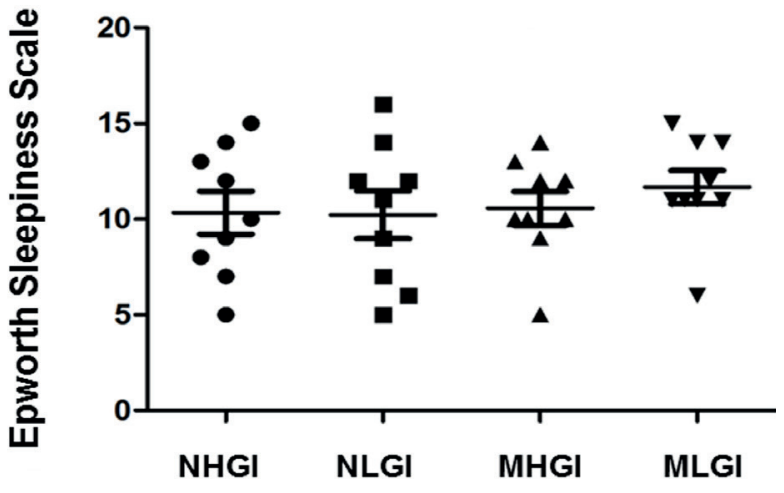

Figure 2 - Daytime sleepiness according to the moments ( $\mathrm{N}=$ night and $\mathrm{M}=$ morning) and GI of the meals (HGI=high glycemic index and LGI=low glycemic index) $(n=9)$.

WASO: $\mathrm{r}=0.71, \mathrm{p}=0.05)$, after HGI. There was a negative correlation between BB cortisol with SSQ $(\mathrm{r}=-0.78 ; \mathrm{p}=0.01)$, after LGI.

There was no difference in melatonin according to GI, only between collection moments in HGI.
Significant differences were found between BD and AA $(\mathrm{p}<0.001)$, and before sleep (BS) and AA $(\mathrm{p}<0.01)$ (Table V).

In HGI, BS melatonin was positively correlated with sleep latency $(r=0.74, p=0.04)$, and in LGI, AA melatonin was negatively correlated with nocturnal total sleep time $(\mathrm{r}=-0.76, \mathrm{p}=0.03)$.

\section{DISCUSSION}

This is the first study to describe the effect of dietary manipulations on athletes' sleep during a competition. The results indicate that the majority of athletes presented poor sleep quality both usually (PSQI assessment) and during competition (actigraphy); the GI manipulation (dinner and ES) did not cause significant differences in sleep parameters; however, energy and nutrient intake 

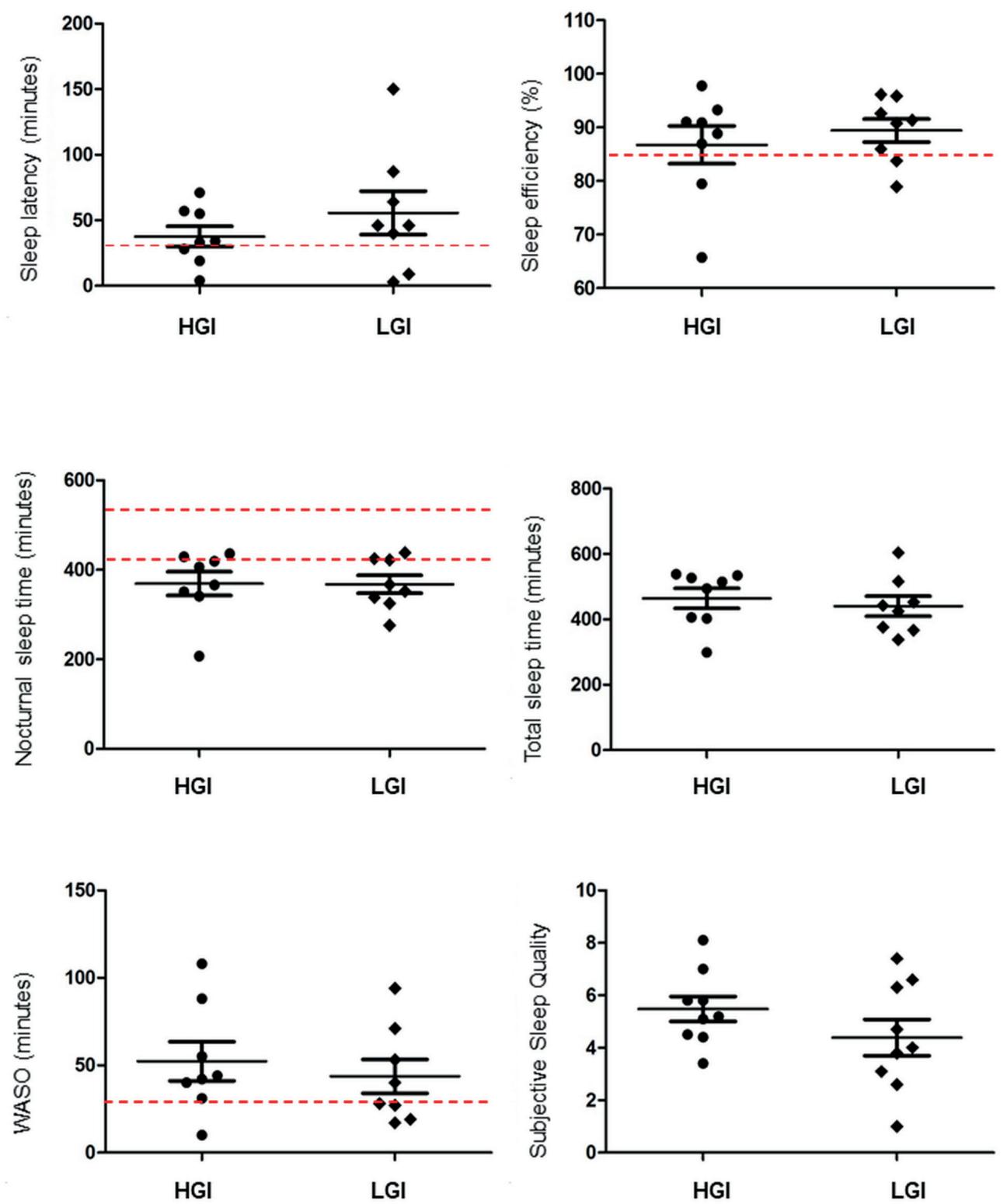

Figure 3 - Effect of different meals (HGI or LGI) on sleep $(n=8)$. WASO=Wake After Sleep Onset. Dotted line indicates recommended values for normal adult sleep (Pinto and Silva 2008).

throughout the whole day seemed to influence sleep. The present study also contributes with information on sleep patterns and cortisol and melatonin responses.

Athletes' intake during intervention, was in accordance to the range of values suggested for collective sports athletes (Holway and Spriet 2011) and the evening meals proposed in this study were carbohydrate-rich ( $>55 \%$ of the meal), as recommended pre-competition (Burke et al. 2011). Although the crossover design in both intervention days, athletes had higher $\mathrm{CHO}$ mean intake in HGI. Nevertheless, the difference $(\mathrm{p}=0.04)$ of daily $\mathrm{CHO}$ intake between HGI and LCI, CHO intake was not correlated with sleep parameters.

Our results are different from other studies with non-athletes, in which carbohydrate-rich meals (Lindseth et al. 2013, Rodrigues 2015), 
TABLE V

Median values of salivary cortisol and melatonin according to the time of collection and GI meals consumed.

\begin{tabular}{lcccc}
\hline Time of collection & \multicolumn{2}{c}{ Salivary cortisol (nmol/L) } & \multicolumn{2}{c}{ Salivary melatonin (pg/mL) } \\
\hline & HGI & LGI & HGI & LGI \\
\cline { 2 - 5 } Before dinner (BD) & $1.7(1.7)^{*}$ & $2.7(2.0)$ & $0.2(0.1) \# \#$ & $0.1(0.3)$ \\
Before sleep (BS) & $0.5(0.5)^{* *}$ & $0.4(0.6) \# \&$ & $0.2(0.2)^{* * *}$ & $0.3(0.3)$ \\
After awakening (AA) & $6.2(4.1)^{* *}$ & $6.4(5.4) \#$ & $2.4(2.3) \# \# * * *$ & $1.3(1.5)$ \\
Before breakfast (BB) & $13.0(4.2)^{*}$ & $8.0(4.2) \&$ & & \\
\hline
\end{tabular}

Values expressed in median (standard deviation).

Significant differences according to HGI and LGI in ${ }^{*} \mathrm{p}<0.05 ;{ }^{*} \mathrm{p}<0.001 ; \# \mathrm{p}<0.01 ; \& \mathrm{p}<0.01 ; \# \# \mathrm{p}<0.001 ; * * * \mathrm{p}<0.01$.

especially HGI (Afaghi et al. 2007) were shown to reduce sleep latency. Our hypothesis that HGI's carbohydrate-rich meals could reduce sleep latency was based on the fact that after a HGI carbohydrate meal intake, there is an increase in the proportion of tryptophan:BCAA through a higher BCAA muscle uptake, due to an increase in insulin secretion in response to the meal (Wurtman et al. 2003). The tryptophan that crosses the blood-brain barrier is converted into serotonin and later into melatonin, so HGI carbohydrate-rich diets may increase melatonin secretion (Wurtman et al. 2003, Afaghi et al. 2007). Although no difference was observed between sleep latency according to the GI, after HGI more athletes presented latency within the recommended values for adults. Even among those athletes with sleep latency above recommended values, the higher values presented after HGI were even lower than after LGI. No association was found between WASO and HGI meals consumption in the literature.

Unhealthy values of athletes' sleep latency and efficiency before and during a competition have also been described in other studies (Shearer et al. 2015, Lastella et al. 2015). These results reinforce the need for greater attention and effort by the technical staff to improve athletes' sleep quality in competitions, especially considering that low sleep quality could impair performance (Oliver et al. 2009).
Actigraphy results showed higher values of sleep latency and efficiency and lower nocturnal total sleep time in comparison to values observed in elite athletes (Leeder et al. 2012). Although the need for sleep duration is individual, when comparing nocturnal total sleep time with the recommended for the age range (420-540 minutes or 7-9 hours) (Hirshkowitz et al. 2015), only $38 \%$ of the athletes slept more than the minimum suggested, on both nights. The nocturnal total sleep time of our study (on both nights) was also lower than observed in other basketball athletes in competition (Mah et al. 2011).

Although sleep plays an important role in exercise recovery (Dattilo et al. 2011), the necessary sleep time for athletes is not defined in the literature. Studies have shown that athletes' sleep duration can vary according to the exercise characteristics (intensity and duration), training sessions schedule and frequency of competitions (Leeder et al. 2012, Lastella et al. 2014). Differences between sports are also highlighted, indicating that in collective sports athletes usually sleep more than those involved in individual disciplines (Leeder et al. 2012, Lastella et al. 2014). Further studies on athletes' sleep are important to elucidate individual needs in this population.

A negative correlation between energy intake and sleep parameters (sleep efficiency and WASO) was found, independent of the GI. Differing from our results, Driver et al. (1999) observed 
that the variation of daily energy consumed did not influence sleep of healthy adults. Although the influence of sleep on energy consumption is reported in the literature (i.e, sleep deprivation causing a consequent energy intake improvement) (Patterson et al. 2014), the consequences of daily energy intake on subsequent sleep are less known, so more investigations are necessary. It is suggested that daily energy intake and its effects on sleep quality are more investigated, especially among athletes, who generally have a high energetic intake compared to sedentary individuals, and may even increase their energy intake pre or during a competitive period.

Athletes in this study presented excessive daytime sleepiness on both days. This was expected as Juliff et al. (2014) pointed out that collective sports athletes have greater daytime sleepiness $(48 \%)$ than individual sports athletes $(27 \%)$. We believe that competition conditions (mattress, noise) may have impaired nocturnal sleep, and this has consequently increased subsequent daytime sleepiness. Considering that athletes had more free time to sleep after lunch than usual, napping may also have increased daytime sleepiness and interfered with subsequent nocturnal sleep, creating a vicious circle.

The association between dietary intake and daytime sleepiness corroborates with the literature, which suggests that a higher carbohydrate intake might increase sleepiness and protein ingestion might reduce it (Spring et al. 1983, Nehme et al. 2014). A greater sleepiness would induce sleep onset, which is desired before bedtime. However, an excessive daytime sleepiness could impair athlete's performance in daily sports activities, thus being undesirable. Distributing macronutrient consumption throughout the day may be an important strategy to control these effects.

Regarding salivary cortisol, the significant difference between collection times was already expected, since cortisol presents a circadian rhythm, with lower secretion at the beginning of the night and peak near to the moment of awakening (Saraiva et al. 2005). Other studies also did not observe difference in cortisol levels according to GI consumed, both in children (Micha et al. 2011) as in young adults (Micha and Nelson 2011) who consumed LGI and HGI meals.

Participants had salivary cortisol AA similar to other basketball athletes $[8.5(2.1) \mathrm{nmol} / \mathrm{L}]$ (Januário et al. 2012) and slightly below soccer athletes [12.4 (2.4) nmol/L] (Minetto et al. 2008). Although several studies investigated cortisol secretion in athletes, the methods and moments of evaluation differ or are not clearly described, so there is need to standardize it for comparison and discussion with reference parameters (Dos Santos et al. 2014).

Cortisol levels in HGI indicated that the higher its BS levels, the worse was sleep quality (lower sleep efficiency and higher WASO), as well as the greater subsequent levels of AA cortisol. Sleep impairment due to cortisol increase was also reported in other studies in healthy and with insomnia adults (Rodenbeck et al. 2002) and in one review (Bush and Hudson 2010), which highlighted that increased levels were associated with awakenings during the night. On the other hand, triathlon athletes' performance was positively correlated with salivary cortisol concentration in the early morning of a competition day (Balthazar et al. 2012). Therefore the relationship between cortisol levels and performance and sleep are not completely understood yet.

Values of salivary melatonin at the three collected moments were below values found in literature (5-20 pg/mL) (Arendt 2011). The highest values (AA) were still below the $10 \mathrm{pg} /$ $\mathrm{mL}$ suggested for this moment (Arendt 2011), but this probably occurred by influence of the ambient luminosity. Even at night, saliva collection occurred while athletes were in the school hall, where the ambient lights were on. This is one of 
the study's limitations, but this factor could not be controlled by the researchers. As known, melatonin has a circadian pattern directly influenced by the presence of light (Arendt 2011), and it has already been reported that a light intensity of incandescent lamps is enough to suppress melatonin secretion at night (Lewy et al. 1980), which was the condition at the collection moment and could have interfered in our results.

The positive correlation between pre-sleeping melatonin secretion and sleep latency after HGI contradicts the findings in the literature, which indicates melatonin as a regulator of the sleep process (Ferracioli-Oda et al. 2013, Gandhi et al. 2015). In the present study, a negative correlation between nocturnal total sleep time and AA melatonin secretion was observed after LGI. According to Bumb et al. (2014), sleep restriction could increase serum melatonin levels up to $75 \%$ in one night of sleep deprivation.

Regarding the correlations between melatonin and food intake, the results also do not corroborate with the literature. The expected increase in the melatonin concentration after HGI intake (Wurtman et al. 2003) was not observed. Considering that sleep is complex and may be related to several aspects (Carskadon and Dement 2011), it is suggested that other factors beyond food intake may have influenced the evaluated parameters. The short time interval between the meal and start of sleep could be a factor that interfered in these results, and perhaps with a longer interval, these expected effects could have been observed.

One of the limitations of the study is the small sample size, which can have influenced the statistical analysis. Furthermore, some collection conditions could not be controlled (e.g. ambient light and noise), which could have influenced the results. However, although researches with a controlled environment can minimize many of these conditions, they have the disadvantage of not representing the situation experienced in practice, being difficult to replicate the dynamics and behaviors that individuals will experience in the field (Gray 2014), therefore the collection in real competition situation has ecological validity and is a positive aspect of this study.

The fact that manipulated meals were proposed according to athletes' habits is another positive aspect. In other studies with meal GI manipulation, the provided food was not their usual meal [i.e. HGI or LGI rice and tomato puree with vegetables (Afaghi et al. 2007); instant mashed potato, boiled eggs and ketchup (HGI) or boiled red lentils (LGI) (Little et al. 2009); instant mashed potatoes (HGI) or müsli (LGI) (Febbraio et al. 2000)]. The interventions were proposed aiming to interfere as little as possible in athletes' activities and behaviors during the competition.

We suggest that further studies should compare sleep during a training period and in competition, and investigate the influence of GI meals of the whole day on sleep, not only the last (dinner and ES) ones.

\section{CONCLUSION}

No significant differences were observed in sleep parameters according to GI meals (dinner and ES) consumed at the night before a competitive basketball game.

Food intake throughout the whole day before competition should be planned, aiming not only to improve athletic performance, but sleep as well. It was observed that the higher the daily energy intake, the worse the sleep quality (lower efficiency and higher WASO), regardless of evening meals' GI. Daily energy consumption and its effects on sleep parameters have to be further investigated, especially among athletes, who generally have a high energy intake.

Based on the contribution of this study, it is expected that new studies in the area could be stimulated and that sports professionals become 
more aware of sleep issues and possible strategies to optimize athletes' sleep.

\section{ACKNOWLEDGMENTS}

This work was supported by the Fundação de Amparo à Pesquisa do Estado de São Paulo (FAPESP), under grant 2014/14276-0; and by Coordenação de Aperfeiçoamento de Pessoal de Nível Superior (CAPES).

\section{AUTHOR CONTRIBUTIONS}

Authors ND, CJ, IZ, and RP are responsible for the conception and design of the study. ND collected all the data. ND, CJ, DE and MG analyzed data and interpreted the results. All authors contributed to the writing of the article, revised it critically and approved the final version.

\section{REFERENCES}

ACSM - AMERICAN COLLEGE OF SPORTS MEDICINE. 2016. American Dietetic Association, Dietitians of Canada. Nutrition and Athletic Performance. Med Sci Sports Exerc 48: 543-568.

AFAGHI A, O'CONNOR H AND CHOW CM. 2007. Highglycemic-index carbohydrate meals shorten sleep onset. Am J Clin Nutr 85: 426-430.

ANTUNES HKM, ANDERSEN ML, TUFIK S AND DE MELLO MT. 2008. Privação de sono e exercício físico. Rev Bras Med Esporte 14: 51-56.

ARENDT J. 2011. The Pineal Gland and Pineal Tumours. In: De Groot LJ, Beck-Peccoz P and Chrousos G (Eds), Endotext. South Dartmouth: MDText.com, Inc.

ATKINSON FS, FOSTER-POWELL K AND BRANDMILLER J. 2008. International tables of glycemic index and glycemic load values: 2008. Diabetes Care 31: 22812283.

BALTHAZAR CH, GARCIA MC AND SPADARIBRATFISCH RC. 2012. Salivary concentrations of cortisol and testosterone and prediction of performance in a professional triathlon competition. Stress 15: 495-502.

BENEDITO-SILVA AA, MENNA-BARRETO L, MARQUES $\mathrm{N}$ AND TENREIRO S. 1990. A self-assessment questionnaire for the determination of morningnesseveningness types in Brazil. Prog Clin Biol Res 341B: 89-98.

BERTOLAZI AN. 2008. Tradução, adaptação cultural e validação de dois instrumentos de avaliação do sono: Escala de Sonolência de Epworth e Índice de Qualidade de Sono de Pittsburgh. Tese de Mestrado. Universidade Federal do Rio Grande do Sul, Porto Alegre. (Unpublished).

BERTOLAZI AN, FAGONDES SC, HOFF LS, PEDRO VD, BARRETO SSM AND JOHNS MW. 2009. Validação da escala de sonolência de Epworth em português para uso no Brasil. J Bras Pneumol 35: 877-883.

BORG GAV. 1982. Psychophysical bases of perceived exertion. Med Sci Sports Exerc 14: 377-381.

BUMB JM, SCHWARZ E, ENNING F, ROHLEDER C, FINDEISEN P, LEWEKE FM AND NOELTE I. 2014. Sleep deprivation in humans: Effects on melatonin in cerebrospinal fluid and serum. Sleep Biol Rhythms 12: 69-72.

BURKE LM, HAWLEY JA, WONG SHS AND JEUKENDRUP AE. 2011. Carbohydrates for training and competition. J Sports Sci 29: S17-S27.

BUSH B AND HUDSON T. 2010. The role of cortisol in sleep. Natural Medicine Journal 2: 26-29.

BUYSSE DJ, REYNOLDS CF, MONK TH, BERMAN SR AND KUPFER DJ. 1989. The Pittsburgh Sleep Quality Index: A Nex Instrument for Psychiatric Practice and Research. Psychiatry Res 28: 193-2013.

CARSKADON MA AND DEMENT WC. 2011. Monitoring And Staging Human Sleep. In: Kryger MH, Roth $\mathrm{T}$ and Dement WC (Eds), Principles and practice of sleep medicine. $5^{\text {th }}$ ed., St. Louis: Elsevier Saunders, p. 16-26.

DATTILO M, ANTUNES HKM, MEDEIROS A, NETO MM, SOUZA HS, TUFIK S AND MELLO MT. 2011. Sleep and muscle recovery: Endocrinological and molecular basis for a new and promising hypothesis. Med Hypotheses 77: 220-220.

DIETHELM K, REMER T, JILANI H, KUNZ C AND BUYKEN AE. 2011. Associations between the macronutrient composition of the evening meal and average daily sleep duration in early childhood. Clin Nutr 30: 640-646.

DOS SANTOS PB, MACHADO TA, OSIECKI ACV, GÓES SM, LEITE N AND STEFANELLO JMF. 2014 A necessidade de parâmetros referenciais de cortisol em atletas: Uma revisão sistemática. Motricidade 10: 107-125.

DRIVER HS, SHULMAN I, BAKER FC AND BUFFENSTEIN R. 1999. Energy content of the evening meal alters nocturnal body temperature but not sleep. Physiol Behav 68: 17-23.

FEBBRAIO MA, KEENAN J, ANGUS DJ, CAMPBELL SE AND GARNHAM AP. 2000. Pre-exercise carbohydrate ingestion, glucose kinetics, and muscle glycogen use: effect of the glycemic index. J Appl Physiol 89: 18451851.

FERRACIOLI-ODA E, QAWASMI A AND BLOCH MH. 2013. Meta-Analysis: Melatonin for the Treatment of Primary Sleep Disorders. PLoS ONE 8: e63773. 
GANDHI AV, MOSSER EA, OIKONOMOU G AND PROBER DA. 2015. Melatonin is required for the circadian regulation of sleep. Neuron 85: 1193-1199.

GRAY DE. 2014. Doing Research in the Real World. $3^{\text {rd }}$ ed., Los Angeles: SAGE.

HALSON SL. 2014. Sleep in elite athletes and nutritional interventions to enhance sleep. Sports Med 44: S13-S23.

HINDMARCH I. 1980. Psychomotor function and psychoactive drugs. Br J Clin Pharmacol 10: 189-209.

HIRSHKOWITZ M, WHITON K, ALBERT SM, ALESSI C, BRUNI O, DONCARLOS L AND HILLARD A. 2015. National Sleep Foundation's sleep time duration recommendations: methodology and results summary. Sleep Health 1: 40-43.

HOLWAY FE AND SPRIET LL. 2011. Sport-specific nutrition: Practical strategies for team sports. J Sports Sci 29: S115-S125.

HORNE JA AND OSTBERG O. 1976. A self-assessment questionnaire to determine morningness-eveningness in human circadian rhythms. Int J Chronobiol 4: 97-110.

ISAK - INTERNATIONAL SOCIETY FOR THE ADVANCEMENT IN KINANTHROPOMETRY. 2001. International Standards for Anthropometric Assessment. Underdale, SA, Australia, p. 1-133.

JACKSON JA AND POLLOCK ML. 1978. Generalized equations for predicting body density of men. Br J Nutr 40: 497-504.

JANUÁRIO WA. 2012. O cortisol salivar como biomarcador de estresse no esporte. Tese de Mestrado. Universidade Federal de São Paulo, São Paulo. (Unpublished).

JULIFF LE, HALSON SL AND PEIFFER JJ. 2015. Understanding sleep disturbance in athletes prior to important competitions. J Sci Med Sport 18: 13-18.

KILLER SC, SVENDSEN IS, JEUKENDRUP AE AND GLEESON M. 2015. Evidence of disturbed sleep and mood state in well-trained athletes during short-term intensified training with and without a high carbohydrate nutritional intervention. J Sports Sci 25: 1-9.

LASTELLA M, LOVELL GP AND SARGENT C. 2014. Athletes' precompetitive sleep behavior and its relationship with subsequent precompetitive mood and performance. Eur J Sport Sci 14: S123-S130.

LASTELLA M, ROACH GD, HALSON SL, MARTIN DT, WEST NP AND SARGENT C. 2015. Sleep/wake behaviour of endurance cyclists before and during competition. J Sports Sci 33: 293-299.

LEEDER J, GLAISTER M, PIZZOFERRO K, DAWSON J AND PEDLAR C. 2012. Sleep duration and quality in elite athletes measured using wristwatch actigraphy. J Sports Sci 30: 541-545.

LEWI AJ, WEHR TA, GOODWIN FK, NEWSOME DAAND MARKEY SP. 1980. Light suppresses melatonin secretion in humans. Science 210: 1267-1269.
LINDSETH G, LINDSETH P AND THOMPSON M. 2013. Nutritional effects on sleep. West J Nurs Res 35: 497-513.

LITTLE JP, CHILIBECK PD, CIONA D, VANDENBERG A AND ZELLO GA. 2009. The effects of low- and high-glycemic index foods on high-intensity intermittent exercise. Int J Sports Physiol Perform 4: 367-380.

MAH CD, MAH KE, KEZIRIAN EJ AND DEMENT WC. 2011. The effects of sleep extension on the athletic performance of collegiate basketball players. Sleep 34: 943-950.

MICHA R AND NELSON M. 2011. Glycemic Index and Glycemic Load Used in Combination to Characterize Metabolic Responses of Mixed Meals in Healthy Lean Young Adults. J Am Coll Nutr 30: 113-125.

MICHA R, ROGERS PJ AND NELSON M. 2011. Glycaemic index and glycaemic load of breakfast predict cognitive function and mood in school children: a randomised controlled trial. Br J Nutr 106: 1552-1561.

MINETTO MA, LANFRANCO F, TIBAUDI A, BALDI M, TERMINE A AND GHIGO E. 2008. Changes in awakening cortisol response and midnight salivary cortisol are sensitive markers of strenuous training-induced fatigue. J Endocrinol Invest 31: 16-24.

NEHME P, MARQUEZE EC, ULHÔA M, MOULATLET E, CODARIN MA AND MORENO CR. 2014. Effects of a carbohydrate-enriched night meal on sleepiness and sleep duration in night workers: A double-blind intervention. Chronobiol Int 31: 453-460.

OLIVER SJ, COSTA RJS, LAING SJ, BILZON JLJ AND WALSH NP. 2009. One night of sleep deprivation decreases treadmill endurance performance. Eur J Appl Physiol 107: 155-161.

PATTERSON RE, EMOND JA, NATARAJAN L, WESSELING-PERRY K, KOLONEL LN, JARDACK P, ANCOLI-ISRAEL S AND ARAB L. 2014. Short sleep duration is associated with higher energy intake and expenditure among African-American and Non-Hispanic white adults. J Nutr 144: 461-466.

PEUHKURI K, SIHVOLA N AND KORPELA R. 2012. Diet promotes sleep duration and quality. Nutr Res 32: 309-319.

RODENBECK A, HUETHER G, RÜTHER E AND HAJAK G. 2002. Interactions between evening and nocturnal cortisol secretion and sleep parameters in patients with severe chronic primary insomnia. Neurosci Lett 324: 159-163.

RODRIGUES DF. 2015. Influência da fase de treinamento sobre parâmetros nutricionais, físicos e psicobiológicos de atletas paraolímpicos brasileiros. Tese de Mestrado. Universidade Federal de São Paulo, São Paulo. (Unpublished).

SARAIVA EM, FORTUNATO JMS AND GAVINA C. 2005. Oscilações do cortisol na depressão e sono/vigília. Revista Portuguesa de Psicossomática 7: 89-100. 
SCOTT JPR, MCNAUGHTON LR AND POLMAN RCJ. 2006. Effects of sleep deprivation and exercise on cognitive, motor performance and mood. Physiol Behav 87: 396-408.

SHEARER DA, JONES RM, KILDUFF LP AND COOK CJ. 2015. Effects of competition on the sleep patterns of elite rugby union players. Eur J Sport Sci 15: 1-8.

SIRI WE. 1961. Body composition from fluids spaces and density: analyses of methods. In: Techniques for measuring body composition. Washington, DC: National Academy of Science and Natural Resource Council.

SPRING B, MALLER O, WURTMAN J, DIGMAN L AND COZOLINO L. 1983. Effects of protein and carbohydrate meals on mood and performance: Interactions with sex and age. J Psychiatr Res 27: 155-167.
TAHERI M AND ARABAMERI E. 2012. The effect of sleep deprivation on choice reaction time and anaerobic power of college student athletes. Asian J Sports Med 3: 15-20.

WOLEVER TMS AND JENKINS DJA. 1986. The use of the glycemic index in predicting the blood glucose response to mixed meals. Am J Clin Nutr 43: 167-172.

WURTMAN RJ, WURTMAN JJ, REGAN MM, MCDERMOTT JM, TSAY RH AND BREU JJ. 2003. Effects of normal meals rich in carbohydrates or proteins on plasma tryptophan and tyrosine ratios. Am J Clin Nutr 77: 128-132.

YONEYAMA S ET AL. 2014. Associations between rice, noodle, and bread intake and sleep quality in Japanese men and women. PLoS ONE 9: e105198. 